\title{
Low preoperative serum ALB level is independently associated with poor overall survival in endometrial cancer patients
}

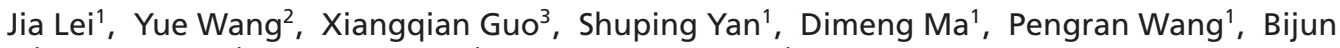 \\ $\mathrm{Li}^{1}$, Wenjun $\mathrm{Du}^{1}$, Ruixia Guo**,1 \& Quancheng Kan*,1 \\ ${ }^{1}$ Department of Gynecologic Oncology, The First Affiliated Hospital of Zhengzhou University, Jianshe East Road, Zhengzhou \\ 450052, PR China \\ ${ }^{2}$ Department of Obstetrics \& Gynecology, Henan Province People's Hospital, 7 Weiwu Road, Zhengzhou 450052, PR China \\ ${ }^{3}$ Department of Preventive Medicine, Institute of Biomedical Informatics, Joint National Laboratory for Antibody Drug Engineering, \\ Cell Signal Transduction Laboratory, School of Basic Medical Sciences, Henan University, Kaifeng 475004, PR China \\ *Author for correspondence: qckan2015@163.com \\ **Author for correspondence: grxcdxzzu@163.com
}

\begin{abstract}
Aim: To reveal the prognostic significance of serum albumin (ALB) concentration in endometrial cancer (EC) patients in China. Patients \& methods: 345 EC patients were enrolled in a single center, and the preoperative serum ALB concentration were measured. Kaplan-Meier curve analysis and Cox proportional hazards regression model were performed to evaluate the associations between ALB concentration and overall survival (OS) of EC patients. Results: The EC patients with lower preoperative serum ALB concentration exhibited a significantly poorer OS $(p<0.05)$. Univariate analysis and multivariate analysis indicated that serum ALB concentration was an independent prognostic factor of unfavorable OS for EC patients. Conclusion: Our results showing that ALB concentration may serve as an independent prognostic factor for EC patients.
\end{abstract}

First draft submitted: 10 November 2019; Accepted for publication: 17 January 2020; Published online: 10 February 2020

Keywords: albumin • gynecological malignancies • Han ethnicity $\bullet$ hypoalbuminemia $\bullet$ multivariate adjustment $\bullet$ nonendometrioid histology $\bullet$ OS • ROC cutoff value $\bullet$ serum $\bullet$ univariate analyses

Gynecological malignancies have become the third leading cause of death in women worldwide [1]. Endometrial cancer (EC), one of the most prevalent gynecological malignancies, accounts for nearly $7 \%$ of new cancer cases and more than $2 \%$ of women deaths in developing countries, especially in China [1,2]. The incidence and mortality rate of EC has increased in recent years [3,4]. For most EC patients diagnosed at an early stage, surgery is the best treatment choice and provides a 5 -year survival of approximately $95 \%$ [5]. However, the 5-year survival rate of latestage EC patients ranges from 16 to $45 \%$ [6,7]. Surgery is often curable for early-stage endometrial cancer [8]. But for the metastatic and recurrent endometrial cancers, hormonal therapy, most commonly progestins, was the only target therapy approved for selected women who are often negative for hormone receptors, with a response rates of up to $20 \%$ in patients [9]. In addition, combination chemotherapy and radiotherapies have been used widespreadly in the treatment of metastatic endometrial cancer, and begun to establish its use in the adjuvant setting in recent trials [10]. The combination chemotherapy group of whole abdomen radiation and doxorubicin can improve progression-free and overall survival (OS), with a hazard ratio (HR) of 0.68 favoring chemotherapy [11]. Recently, immunotherapy is applied to inhibit EC though the restoration of the immune system. The checkpoint inhibitor, pembrolizumab, has been approved by the US FDA for metastatic EC (MMR-deficient) with the objective response rate (ORR) ranges from 13 to $48 \%$ [12].

As incomplete response of single treatment modalities, a combinatory approach grouping chemotherapy, molecular-targeted therapy and radiotherapy, may persuade a synergistic effect and could also be viable treatment option [13]. Previous studies have found that some factors may be prognostic biomarkers for EC patients, such 
as CA125, CEA and CA199. However, these markers may also change in other cancers, except endometrial cancer. Therefore, novel prognostic biomarkers for predicting clinical outcomes of EC patients are urgently needed.

Albumin (ALB) constitutes about half of serum proteins. ALB has been involved in scavenging free radicals, maintaining colloid osmotic pressure and protecting neuronal cells, and is closely related to nutritional status and systemic inflammatory response [14]. Recent studies reported that hypoalbuminemia was predominantly observed in cancer patients and was considered as a prognostic marker in human cancers, such as lung cancer [15], breast cancer [16], ovarian cancer [17] and colorectal cancer [18]. In addition, serum ALB concentration are associated with survival outcomes of renal cancer [19], non-small-cell lung cancer [20], nonmetastatic breast cancer [21], gastric cancer [22] and urothelial carcinoma [23]. However, the prognostic value of serum ALB concentration in EC patients remains unclear.

In this study, we measured the preoperative serum ALB concentration in EC patients and evaluated the association between preoperative serum ALB concentration and OS of EC patients.

\section{Patients \& methods}

Subjects

A total of 471 Han Chinese patients with EC cancer were enrolled at the First Affiliated Hospital of Zhengzhou University, China, between March 2012 and November 2017. All patients had newly diagnosed EC confirmed by histological examination and received primary surgery. None of the patients had a cancer history or other cancerrelated treatments. Serum ALB was assayed using routine clinical chemical photometric analyzers as previously described [24]. 60 patients with incomplete clinical information or without follow-up data and patients with nonendometrioid histology (such as dysplasia, uterine sarcoma, papillary serous, clear cell, serous adenocarcinoma and endometrial carcinosarcoma) or without ALB determination were excluded. Finally, a total of 345 EC patients, whose ALB values were measured one week before surgery, were included in the cohort for further analysis. Physicians collected detailed clinical information including age, histological grade, the 2009 International Federation of Gynecology and Obstetrics (FIGO) stage, depth of myometrial invasion, lymph node metastasis and menopausal status through reviewing medical chart. A trained clinical specialist followed these patients through direct calling, medical chart review or on-site interview. The latest follow-up data in this analysis were collected in November 2017. OS was defined as the interval from the surgery to the date of death or last follow-up. All patients had signed informed consent in the study. This study was approved by Ethics Committee of First Affiliated Hospital of Zhengzhou University and the Ethics certificate number is 2018-KY-41.

\section{Statistical analysis}

SPSS version 20.0 software package (IBM, NY, USA) was used for statistical analysis. Univariate and multivariate analyses were performed using the Cox proportional hazards regression model. Kaplan-Meier curve analysis was used to calculate cumulative survival time for patients in different subgroup. Log-rank test was used to analyze the difference in survival time between groups. $\mathrm{p}<0.05$ in two-sided tests was considered statistically significant in this study.

\section{Results}

\section{Characteristics of enrolled EC patients}

In this study, 345 EC patients were analyzed according to the procedure shown in Figure 1. Demographic and clinical characteristics of all patients are summarized in Table 1. All patients were Chinese of Han ethnicity with a median age of 53.1 years. Initial clinical stage of patients was performed using the FIGO staging system [25]. Histological stratification was determined using the criteria of the World Health Organization Histological Grading System for Tumors [26]. The 315 cases of myometrial invasion with a depth of $\leq 1 / 2$ include 304 cases (stage I-II) and 11 cases in stage III who have lymph node metastasis but with the depth of myometrial invasion $\leq 1 / 2$. The 323 cases without lymph node metastasis include 304 cases (stage I-II), and 19 cases in stage III/IV who have local transfer or distant metastasis but without lymph node metastasis. Among them, there were $88.1 \%$ of patients with stage I-II tumors $(\mathrm{n}=304)$ and $41.2 \%$ of patients with G1 tumors $(\mathrm{n}=142)$. The majority of patients had myometrial invasion with a depth of $\leq 1 / 2(\mathrm{n}=315,91.3 \%)$ and without lymph node metastasis $(\mathrm{n}=323$, 93.6\%). Moreover, 44 (12.8\%) patients had family cancer history, 138 (40.0\%) patients received chemotherapy, $126(36.5 \%)$ patients had gynecological surgery history and $193(55.9 \%)$ patients were in postmenopausal status, more than $50 \%$ of our patients have co-morbidities, mostly diabetes or hypertension. During the follow-up period, 


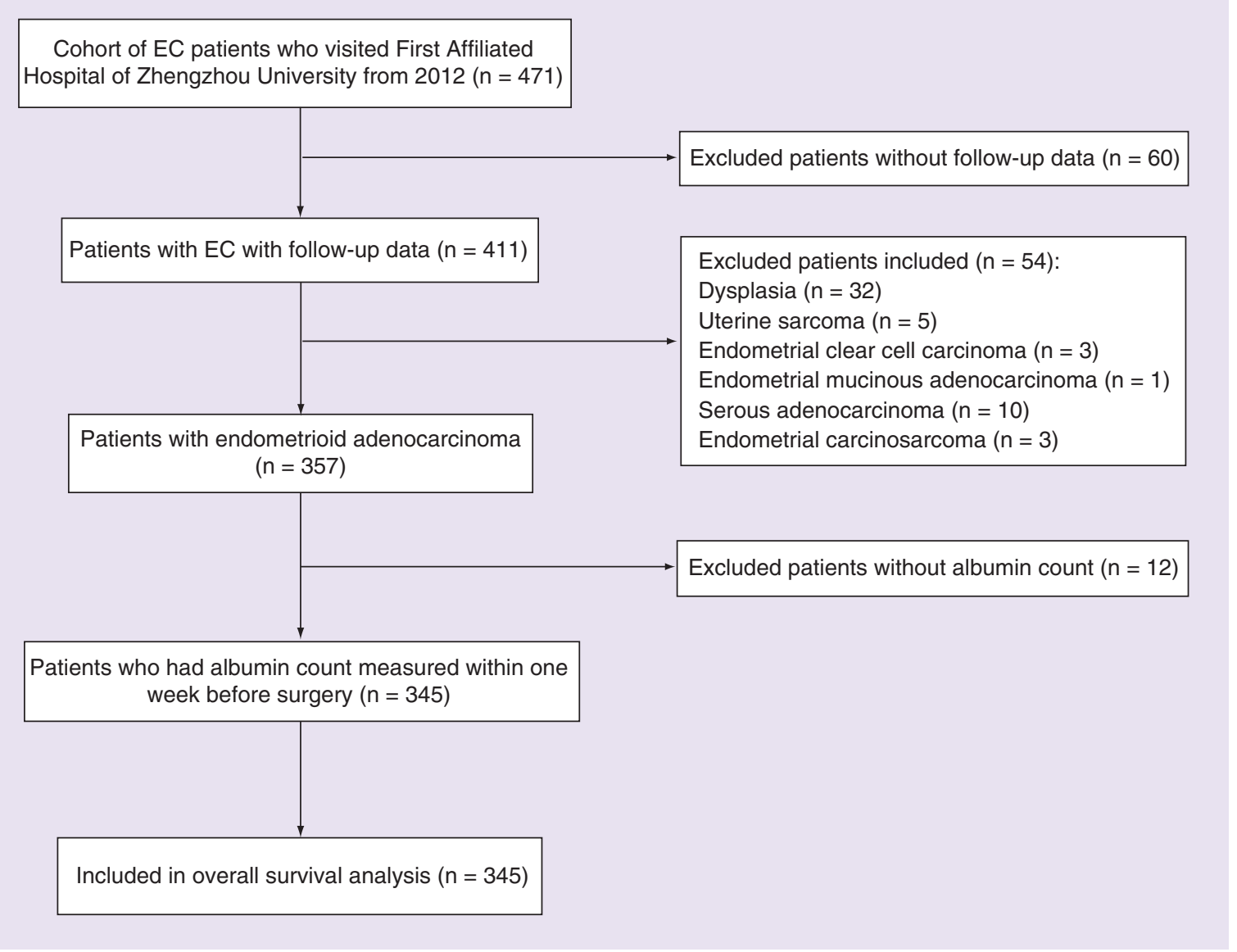

Figure 1. Flow chart of patient's recruitment.

17 (4.9\%) patients died (13 patients died of recurrence or metastasis of EC, four patients died of other causes) and $33(9.6 \%)$ patients experienced recurrence (Table 1). When collecting patients' data, some patients with incomplete information were classified as unknown.

\section{Prognostic significance of clinical characteristics for EC patients}

Univariate and multivariate analyses were performed to assess the association between clinical characteristics and OS in EC patients. As shown in Table 2, advanced-stage (stage III-IV; HR: 5.86; 95\% CI: 2.12-16.22; p = 0.001) and depth of myometrial invasion $>1 / 2$ (HR: 6.54; 95\% CI: 2.25-18.95; $\mathrm{p}=0.001$ ) were significantly associated with the poor OS of EC patients. In addition, the risk of poor OS also increased in older patients (HR: 5.50; 95\% CI: 1.57-19.22; $\mathrm{p}=0.008$ ), patients with G3 tumors (HR: 4.18; 95\% CI: 1.27-13.77; $\mathrm{p}=0.019$ ), patients with lymph node metastasis (HR: 4.13; 95\% CI: 1.17-14.58; $\mathrm{p}=0.028$ ) and menopause patients (HR: 5.23 ; 95\% CI: 1.19-22.91; $\mathrm{p}=0.028$ ). However, independent prognostic predictors were not obtained after performing multivariate analysis to control for these variables (Table 2).

\section{Prognostic analysis of preoperative serum ALB concentration in EC patients}

To investigate the prognostic significance of preoperative serum ALB concentration on OS of EC patients, we divided the patients into two subgroups by the ALB clinical cutoff $(34.00 \mathrm{~g} / \mathrm{l})$, median $(41.90 \mathrm{~g} / \mathrm{l})$ or ROC cutoff value $(37.65 \mathrm{~g} / \mathrm{l})$. The association between preoperative serum ALB concentration and OS was evaluated by Cox regression model using univariate and multivariate analyses. As shown in Table 3, there was no significant association between OS of EC patients and preoperative serum ALB concentration when divided by the median, whereas the significant association between OS and preoperative serum ALB concentration was observed when patients were divided by ROC cutoff value or clinical cutoff. After multivariate adjustment, the association still 
Table 1. Clinical characteristics of endometrial cancer patients.

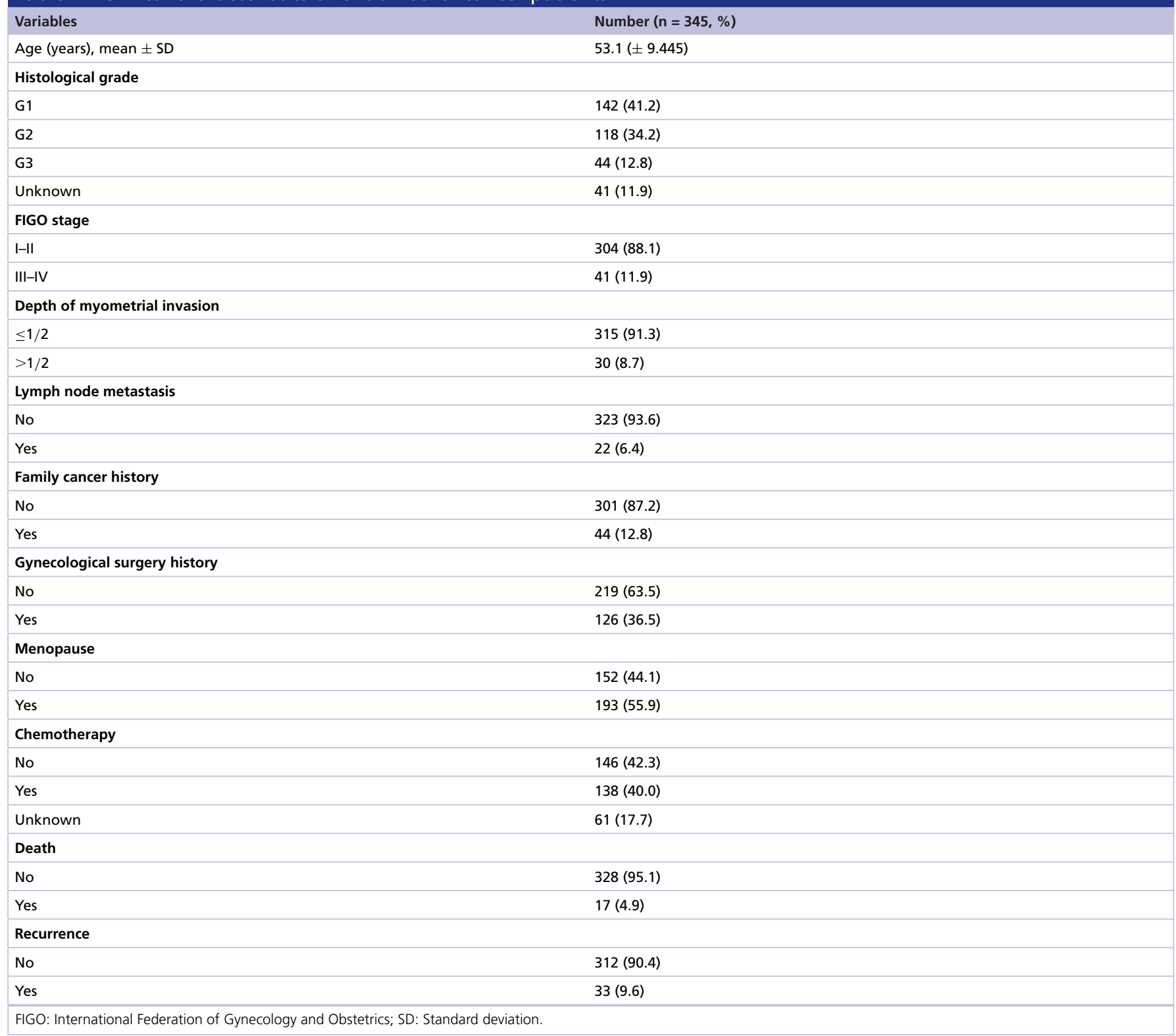

persisted when the ROC cutoff value of preoperative serum ALB concentration was used (HR: 7.81, 95\% CI: 1.89-32.36; $\mathrm{p}=0.005)$. We then performed stratified analysis based on ROC cutoff value. Kaplan-Meier curve analysis demonstrated that EC patients with high ALB concentration had a significantly longer OS than those with low ALB concentration (Figure 2).

Prognostic analysis of preoperative serum ALB concentration in EC patients stratified by host characteristics

To further evaluate the effects of these clinical characteristics on the association between ALB concentration and OS, we conducted stratified analysis by host variables (Table 4). In univariate analyses, the significant association between low preoperative serum ALB concentration and poor OS was observed in older patients $(\mathrm{p}=0.006)$, G1-G2 patients $(\mathrm{p}=0.036)$, stage I-II patients $(\mathrm{p}=0.009)$, muscular infiltration depth $\leq 1 / 2(\mathrm{p}=0.004)$, no lymph node metastasis patients $(\mathrm{p}=0.001)$ and menopause patients $(\mathrm{p}=0.018)$. Similar results were obtained after multivariate adjustment. As shown in Figure 3, Kaplan-Meier curve analysis also showed that the patients with older age, lower histological grade (G1-G2) and FIGO (I-II) stage, muscular infiltration depth $\leq 1 / 2$, without 


\begin{tabular}{|c|c|c|c|c|c|c|}
\hline \multirow[t]{2}{*}{ Characteristic } & \multirow{2}{*}{$\begin{array}{l}\text { Total number } \\
\text { of patients, \% (345) }\end{array}$} & \multirow{2}{*}{$\begin{array}{l}\text { Number of dead } \\
\text { patients, \% (17) }\end{array}$} & \multicolumn{2}{|c|}{ Univariate } & \multicolumn{2}{|c|}{ Multivariate $^{\dagger}$} \\
\hline & & & HR (95\% Cl) & $p$-value & HR $(95 \% \mathrm{Cl})$ & $p$-value \\
\hline \multicolumn{7}{|l|}{ Age (years) } \\
\hline$\leq 53$ & $190(55.0)$ & $3(17.6)$ & 1.00 & & 1.00 & \\
\hline$>53$ & $155(44.9)$ & $14(82.4)$ & $5.50(1.57-19.22)$ & 0.008 & $3.33(0.54-20.37)$ & 0.193 \\
\hline \multicolumn{7}{|c|}{ Histological grade } \\
\hline G1-G2 & $260(75.3)$ & $3(17.6)$ & 1.00 & & 1.00 & \\
\hline G3 & $44(12.6)$ & $4(23.5)$ & $4.18(1.27-13.77)$ & 0.019 & $1.54(0.43-5.47)$ & 0.504 \\
\hline Unknown & $41(11.9)$ & $10(58.8)$ & & & & \\
\hline \multicolumn{7}{|l|}{ FIGO stage } \\
\hline $\mid-11$ & $304(88.1)$ & $11(64.7)$ & 1.00 & & 1.00 & \\
\hline III-IV & $41(11.9)$ & $6(35.3)$ & $5.86(2.12-16.22)$ & 0.001 & $7.19(1.85-27.92)$ & 0.004 \\
\hline \multicolumn{7}{|c|}{ Depth of myometrial invasion } \\
\hline$\leq 1 / 2$ & $315(91.3)$ & $12(70.6)$ & 1.00 & & 1.00 & \\
\hline$>1 / 2$ & $30(8.6)$ & $5(29.4)$ & $6.54(2.25-18.95)$ & 0.001 & $3.61(0.98-13.30)$ & 0.054 \\
\hline \multicolumn{7}{|c|}{ Lymph node metastasis } \\
\hline No & $323(93.7)$ & $14(82.4)$ & 1.00 & & 1.00 & \\
\hline Yes & $22(6.3)$ & $3(17.6)$ & $4.13(1.17-14.58)$ & 0.028 & $2.79(0.45-17.11)$ & 0.268 \\
\hline \multicolumn{7}{|l|}{ Menopause } \\
\hline No & $152(44.0)$ & $2(11.8)$ & 1.00 & & 1.00 & \\
\hline Yes & $193(66.0)$ & $15(88.2)$ & $5.23(1.19-22.91)$ & 0.028 & $1.23(0.15-10.08)$ & 0.850 \\
\hline
\end{tabular}

Table 3. The association between preoperative serum albumin levels and clinical outcomes of endometrial cancer patients.

\begin{tabular}{|c|c|c|c|c|c|c|}
\hline \multirow[t]{2}{*}{ ALB values } & \multirow[t]{2}{*}{ Alive } & \multirow[t]{2}{*}{ Dead } & \multicolumn{2}{|c|}{ Univariate } & \multicolumn{2}{|c|}{ Multivariate $^{\dagger}$} \\
\hline & & & HR $(95 \% \mathrm{Cl})$ & p-value & $\mathrm{HR}(95 \% \mathrm{Cl})$ & $\mathrm{p}$-value \\
\hline \multicolumn{7}{|l|}{ By median } \\
\hline$>$ Median (41.90) & 166 & 6 & 1 & & 1 & \\
\hline$\leq$ Median (41.90) & 62 & 11 & $1.64(0.61-4.43)$ & 0.332 & $1.50(0.52-4.28)$ & 0.450 \\
\hline \multicolumn{7}{|l|}{ By clinical cutoff } \\
\hline$\geq 34.00$ & 318 & 14 & 1 & & 1 & \\
\hline$<34.00$ & 10 & 3 & $6.988(1.987-24.576)$ & 0.002 & $3.244(0.495-21.245)$ & 0.220 \\
\hline \multicolumn{7}{|c|}{ By ROC cutoff value } \\
\hline$\geq 37.65$ & 283 & 9 & 1 & & 1 & \\
\hline$<37.65$ & 45 & 8 & $5.20(1.98-13.63)$ & 0.001 & $7.81(1.89-32.36)$ & 0.005 \\
\hline
\end{tabular}

lymph node metastasis and in postmenopausal status exhibited poor OS when their preoperative serum ALB values were at a low level.

\section{Discussion}

In this study, we evaluated the prognostic value of preoperative serum ALB concentration in a hospital-based cohort of 345 EC patients. We found that patients with low preoperative serum ALB concentration were associated with poor OS, suggesting that preoperative serum ALB concentration may serve as an independent prognostic factor for EC patients.

ALB is a routine detection index of liver function test in clinical work, and is closely related to the nutritional status and systemic inflammatory response of patients [14], particularly in cancer patients [27]. It has been reported that ALB is involved in several mechanisms of cancer development and therapy. First, the serum ALB concentration 


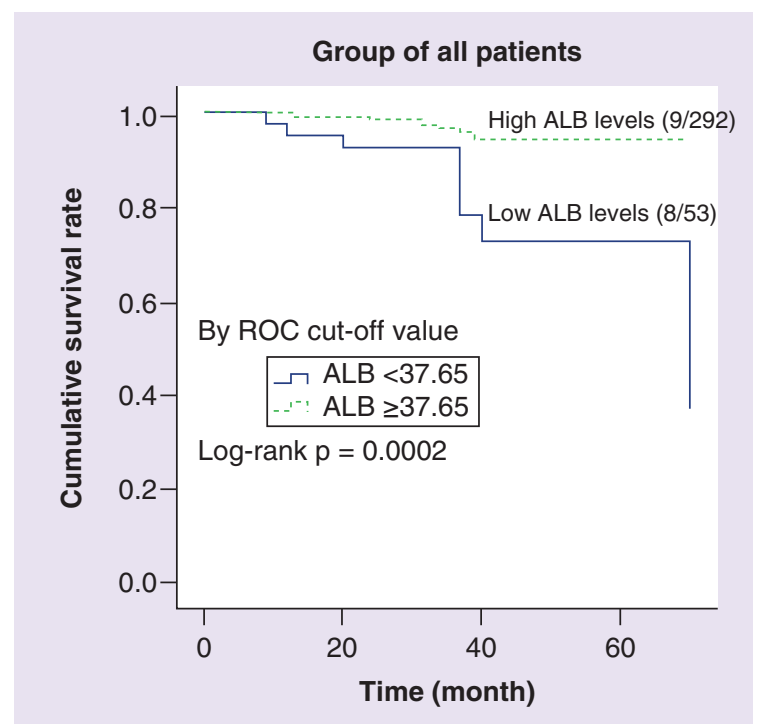

Figure 2. Kaplan-Meier curves of overall survival analyses in endometrial cancer patients.

might reflect the status of chronic inflammation. Previous studies have demonstrated that the production of ALB is markedly inhibited in the process of cancer-related systemic inflammation, which is modulated by a variety of cytokines and growth factors produced by tumor cells and immune cells [28,29]. Second, low-serum ALB concentration, which may reflect poor nutritional status of cancer patients, are closely associated with chemotherapy tolerance and response [30]. Furthermore, ALB might be involved in antioxidant function and anticancer effect [31,32]. In addition, the differences in mRNA expression of ALB between tumor and normal tissue in multiple cancers were determined by Oncomine (www.oncomine.org). The database contained a total of 420 unique analyses for ALB. As per gene summary view, a total of 31 analyses comprising breast cancer, colorectal cancer, gastric cancer, kidney cancer and sarcoma - among others, which showed statistically significant reduction at ALB mRNA expression concentration in tumor, while 21 analyses including bladder cancer, brain and CNS cancer-among others, showed an increased expression of ALB mRNA (Supplementary Figure 1). The serum ALB concentration are associated with survivals of various cancers, including renal cancer [19], stage I non-small-cell lung cancer [20], nonmetastatic breast cancer [21], gastric cancer [22] and urothelial carcinoma [23]. For EC, only Seebacher et al. [33] explored the prognostic value of serum ALB in white EC patients, and found that low pretreatment serum ALB level was an independent prognostic parameter for disease-free and progression-free survival in EC patients. However, the prognostic value of serum ALB in Asian EC patients was still unknown. In our study, the prognostic value of serum ALB in EC patients in China was investigated, and we found that low preoperative serum ALB concentration was significantly associated with poor prognosis of EC patients, which is in accordance with previous study [33]. These results indicated that serum ALB may be an independent prognostic marker for EC patients across the race.

In the stratified analyses, we found that lower preoperative serum ALB concentration was significantly associated with poor OS in patients with early FIGO (I-II) stage tumor, without lymph node metastasis, at an older age, or in postmenopausal status. These results indicated that preoperative serum ALB concentration might be modulated by host characteristics. However, the molecular mechanisms modulated circulating ALB concentration in cancer patients is still unclear. The proinflammatory cytokine secretion caused by systemic inflammation may affect hepatic function of cancer patients and inhibit synthesis of ALB [34,35]. TNF- $\alpha$, a cytokine known as a mediator of inflammation and cancer-related cachexia, has been reported to be elevated and to promote invasion and metastasis of EC [36]. TNF- $\alpha$ has also been reported to inhibit ALB synthesis in a murine model of cachexia [37]. This might explain the impact of serum ALB concentration on prognosis even in early-stage disease. FIGO stage might reflect an inflammatory response caused by tumor load in EC patients, which may affect the production of ALB.

There are several limitations in our present study. First, enrolled patients were restricted to Han Chinese and just from one single center, large-scale multicenter studies including other ethnic cohort are necessary to validate our findings. In addition, the levels of some specific inflammatory markers are not evaluated in this study, for example, $\mathrm{C}$-reactive protein and the inflammatory cytokine. The underlying mechanisms that account for varied serum ALB concentration in EC patients need to be further investigated. 
(A)

Subgroup of age $>53$



(C)

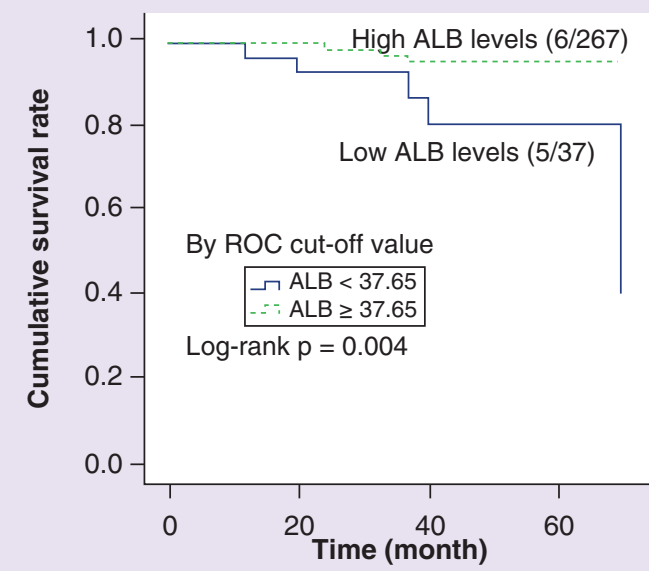

(E) Subgroup of lymph node no-metastasis

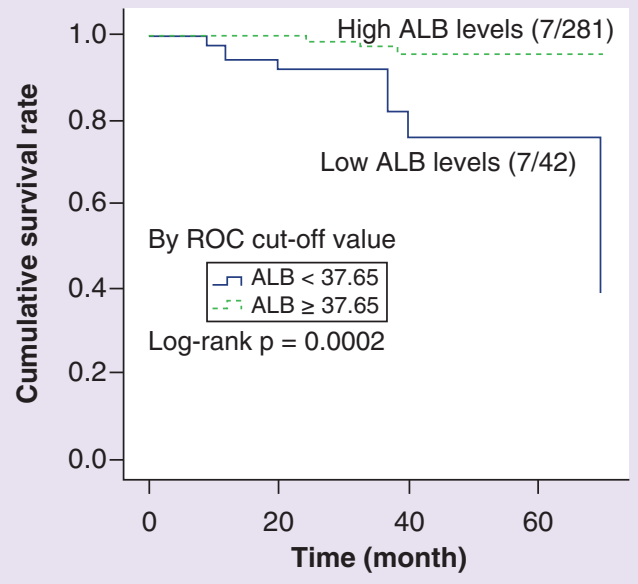

(B) Subgroup of histological grade G1, G2

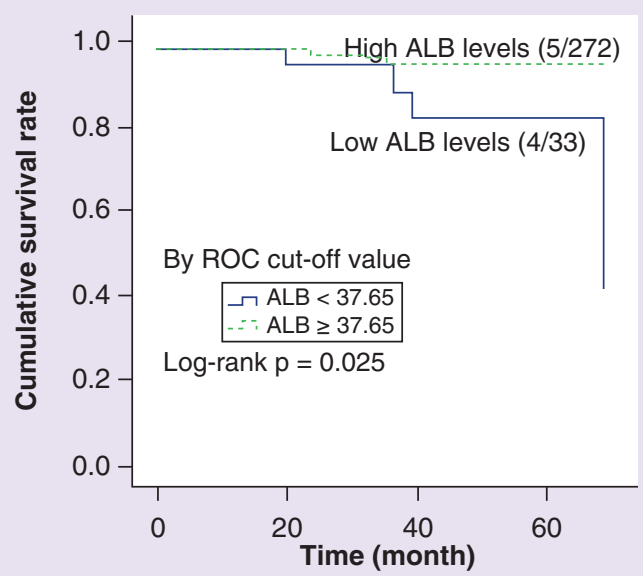

(D) Subgroup of depth of myometrial invasion $<1 / 2$

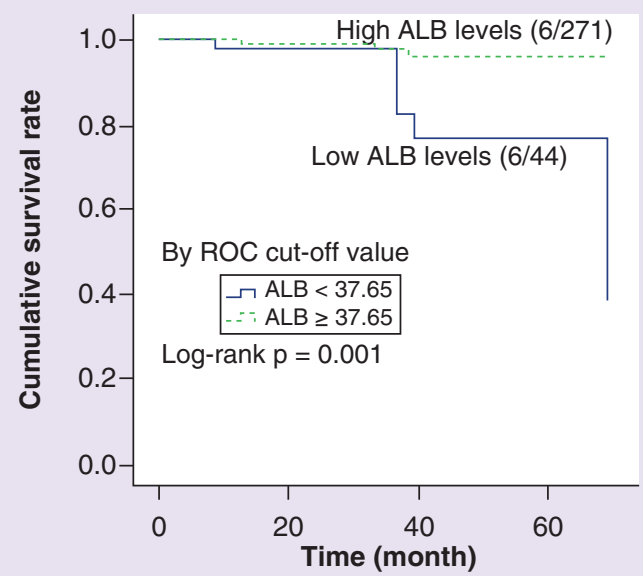

(

Subgroup of menopause

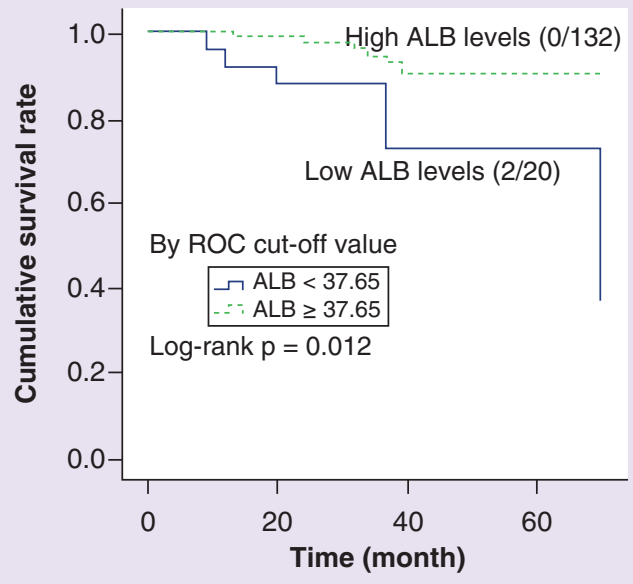

Figure 3. Kaplan-Meier curves of overall survival analyses in different subgroup endometrial cancer patients. (A) In patients with age more than 53; (B) in patients with histological grade of GI-G2; (C) in patients with FIGO stage of I-II; (D) in patients with muscular infiltration depth $\leq 1 / 2 ;(E)$ in patients without lymph metastasized; and (F) in patients in menopausal.

FIGO: International Federation of Gynecology and Obstetrics. 
Table 4. The association between preoperative serum albumin levels and overall survival stratified by patients' characteristics.

\begin{tabular}{|c|c|c|c|c|c|c|c|}
\hline \multirow[t]{2}{*}{ Characteristic } & \multirow[t]{2}{*}{ ALB values } & \multirow[t]{2}{*}{ Patients (n) } & \multirow{2}{*}{$\begin{array}{l}\text { Dead patients } \\
\text { (n) }\end{array}$} & \multicolumn{2}{|c|}{ Univariate } & \multicolumn{2}{|c|}{ Multivariate $^{\dagger}$} \\
\hline & & & & HR (95\% Cl) & p-value & HR (95\% Cl) & p-value \\
\hline \multicolumn{8}{|l|}{ Age (years) } \\
\hline \multirow[t]{2}{*}{ Younger ( $\leq 53$ years) } & $\geq 37.65$ & 168 & 2 & 1.00 & & 1.00 & \\
\hline & $<37.65$ & 22 & 1 & $4.46(0.41-49.22)$ & 0.222 & $6.10(0.21-176.73)$ & 0.292 \\
\hline \multirow[t]{2}{*}{ Older (>53 years) } & $\geq 37.65$ & 130 & 7 & 1.00 & & 1.00 & \\
\hline & $<37.65$ & 25 & 7 & $4.39(1.51-12.72)$ & 0.006 & $6.41(1.84-22.33)$ & 0.004 \\
\hline \multicolumn{8}{|l|}{ Histological grade } \\
\hline \multirow[t]{2}{*}{ G1-G2 } & $\geq 37.65$ & 227 & 5 & 1.00 & & 1.00 & \\
\hline & $<37.65$ & 33 & 4 & $4.30(1.10-16.80)$ & 0.036 & $4.52(1.00-20.49)$ & 0.051 \\
\hline \multirow[t]{2}{*}{ G3 } & $\geq 37.65$ & 38 & 2 & 1.00 & & & \\
\hline & $<37.65$ & 6 & 2 & $5.84(0.81-42.13)$ & 0.080 & NA & \\
\hline \multicolumn{8}{|l|}{ FIGO stage } \\
\hline \multirow[t]{2}{*}{ I-II } & $\geq 37.65$ & 267 & 6 & 1.00 & & 1.00 & \\
\hline & $<37.65$ & 37 & 5 & $5.04(1.50-16.93)$ & 0.009 & $6.87(1.76-26.90)$ & 0.006 \\
\hline \multirow[t]{2}{*}{ III-IV } & $\geq 37.65$ & 31 & 3 & 1.00 & & 1.00 & \\
\hline & $<37.65$ & 10 & 3 & $4.23(0.81-22.31)$ & 0.088 & $2.36(0.21-26.45)$ & 0.486 \\
\hline \multicolumn{8}{|c|}{ Depth of myometrial invasion } \\
\hline \multirow[t]{2}{*}{$\leq 1 / 2$} & $\geq 37.65$ & 271 & 6 & 1.00 & & 1.00 & \\
\hline & $<37.65$ & 44 & 6 & $5.41(1.71-17.05)$ & 0.004 & $3.38(0.96-11.85)$ & 0.057 \\
\hline \multirow[t]{2}{*}{$>1 / 2$} & $\geq 37.65$ & 27 & 3 & & & & \\
\hline & $<37.65$ & 3 & 2 & NA & & NA & \\
\hline \multicolumn{8}{|c|}{ Lymph node metastasis } \\
\hline \multirow[t]{2}{*}{ No } & $\geq 37.65$ & 281 & 7 & 1.00 & & 1.00 & \\
\hline & $<37.65$ & 42 & 7 & $5.92(2.04-17.11)$ & 0.001 & $6.42(1.97-20.91)$ & 0.002 \\
\hline \multirow[t]{2}{*}{ Yes } & $\geq 37.65$ & 17 & 2 & 1.00 & & 1.00 & \\
\hline & $<37.65$ & 5 & 1 & $3.74(0.28-61.59)$ & 0.356 & $1.98(0.04-106.39)$ & 0.737 \\
\hline \multicolumn{8}{|l|}{ Menopause } \\
\hline \multirow[t]{2}{*}{ No } & $\geq 37.65$ & 132 & 0 & & & & \\
\hline & $<37.65$ & 20 & 2 & NA & & NA & \\
\hline \multirow[t]{2}{*}{ Yes } & $\geq 37.65$ & 166 & 9 & 1.00 & & 1.00 & \\
\hline & $<37.65$ & 27 & 6 & $3.58(1.24-10.29)$ & 0.018 & $4.60(1.39-15.28)$ & 0.013 \\
\hline
\end{tabular}

\section{Conclusion}

Preoperative serum ALB concentration may serve as a promising prognosis biomarker for EC patients undergoing surgical resection.

\section{Summary points}

- Endometrial cancer (EC), one of the most prevalent gynecological malignancies, accounts for nearly $7 \%$ of new cancer cases and more than $2 \%$ of women deaths in developing countries, especially in China.

- This study enrolled 345 EC patients, measured their serum concentration of albumin, and evaluated the prognostic values of this serological indicator in EC patients by Kaplan-Meier curve analysis and Cox proportional hazards regression model.

- Serum albumin concentration might be an independent prognostic marker for EC patients. 


\section{Author contributions}

J Lei, R Guo and Q Kan were responsible for the study concept and design. J Lei, Y Wang, X Guo, S Yan, D Ma and P Wang contributed to the acquisition of data. J Lei, B Li, W Du, R Guo and Q Kan performed the analysis and interpretation of data. J Lei, R Guo and Q Kan drafted the manuscript. J Lei, R Guo and Q Kan contributed to the critical revision of the manuscript for intellectual content.

Financial \& competing interests disclosure

This work was supported by the National Natural Science Foundation of China (no. 31670844). The authors have no other relevant affiliations or financial involvement with any organization or entity with a financial interest in or financial conflict with the subject matter or materials discussed in the manuscript apart from those disclosed.

No writing assistance was used in the creation of this manuscript.

\section{Ethical conduct of research}

The authors have no relevant affiliations or financial involvement with any organization or entity with a financial interest in or financial conflict with the subject matter or materials discussed in the manuscript. This includes employment, consultancies, honoraria, stock ownership or options, expert testimony, grants or patents received or pending, or royalties.

\section{Reference}

1. Torre LA, Bray F, Siegel RL et al. Global cancer statistics, 2012. CA Cancer J. Clin. 65(2), 87-108 (2015).

2. Wei KR, Chen WQ, Zhang SW et al. Epidemiology of uterine corpus cancer in some cancer registering areas of China from $2003-2007$. Zhonghua Fu Chan Ke Za Zhi. 47(6), 445-451 (2012).

3. Gaber C, Meza R, Ruterbusch JJ et al. Endometrial cancer trends by race and histology in the USA: projecting the number of new cases from 2015 to 2040. J. Racial Ethn. Health Disparities 4(5), 895-903 (2016).

4. Lortet-Tieulent J, Ferlay J et al. International patterns and trends in endometrial cancer incidence, 1978-2013. J. Natl Cancer I. 110(4), 354-361 (2018).

5. Frandsen JE, Sause WT, Dodson MK et al. Survival analysis of endometrial cancer patients with cervical stromal involvement. J. Gynecol. Oncol. 25(2), 105-110 (2014).

6. Clarke MA, Long BJ, Del Mar Morillo A et al. Association of endometrial cancer risk with postmenopausal bleeding in women: a systematic review and meta-analysis. JAMA Intern. Med. 178(9), 1210-1222 (2018).

7. Weiderpass E, Antoine J, Bray FI et al. Trends in corpus uteri cancer mortality in member states of the European Union. Eur. J. Cancer 50(9), 1675-1684 (2014).

8. Einstein MH, Rice LW. Current surgical management of endometrial cancer. Hematol. Oncol. Clin. North Am. 26(1), 79-91 (2012).

9. Wright JD, Barrena Medel NI, Sehouli J et al. Contemporary management of endometrial cancer. Lancet 379(9823), 1352-1360 (2012).

10. Yoshida H, Imai Y, Fujiwara K. Combination chemotherapy with docetaxel and carboplatin for elderly patients with endometrial cancer. Mol. Clin. Oncol. 4(5), 783 (2016).

11. Ngan HYS, Odicino F, Maisonneuve P et al. Gestational trophoblastic neoplasia. FIGO 26th Annual Report on the Results of Treatment in Gynecological Cancer. Int. J. Gynecol. Obestet. 95, 193-203 (2006).

12. Makker V, Rasco DW, Dutcus CE et al. A Phase Ib/II trial of lenvatinib (LEN) plus pembrolizumab (Pembro) in patients (Pts) with endometrial carcinoma. J. Clin. Oncol. 35, (2017).

13. Mellman I, Coukos G, Dranoff G. Cancer immunotherapy comes of age. Nature 480, 480-489 (2011).

14. Margarson MP, Soni N. Serum albumin: touchstone or totem? Anaesthesia 53(8), 789-803 (1998).

15. Brown DJ, Milroy R, Preston T et al. The relationship between an inflammation-based prognostic score (Glasgow Prognostic Score) and changes in serum biochemical variables in patients with advanced lung and gastrointestinal cancer. J. Clin. Pathol. 60(6), 705-708 (2007).

16. Al Murri AM, Bartlett JM, Canney PA et al. Evaluation of an inflammation-based prognostic score (GPS) in patients with metastatic breast cancer. Brit. J. Cancer. 94(2), 227-230 (2006).

17. Sharma R, Hook J, Kumar M, Gabra H. Evaluation of an inflammation-based prognostic score in patients with advanced ovarian cancer. Eur. J. Cancer 44(2), 251-256 (2008).

18. Al-Shaiba R, McMillan DC, Angerson WJ et al. The relationship between hypoalbuminaemia, tumour volume and the systemic inflammatory response in patients with colorectal liver metastases. Brit. J. Cancer 91(2), 205-207 (2004).

19. Stenman M, Laurell A, Lindskog M. Prognostic significance of serum albumin in patients with metastatic renal cell carcinoma. Med. Oncol. 31(3), 841 (2014). 
20. Jin Y, Zhao L, Peng F. Prognostic impact of serum albumin levels on the recurrence of stage I non-small cell lung cancer. Clinics 68(5), 686-693 (2013).

21. Liu X, Meng QH, Ye Y et al. Prognostic significance of pretreatment serum levels of albumin, LDH and total bilirubin in patients with non-metastatic breast cancer. Carcinogenesis 36(2), 243-248 (2015).

22. Sun $\mathrm{H}, \mathrm{He} \mathrm{B}, \mathrm{Nie} \mathrm{Z}$ et al. A nomogram based on serum bilirubin and albumin levels predicts survival in gastric cancer patients. Oncotarget. 8(25), 41305-41318 (2017).

23. Liu J, Wang F, Li S et al. The prognostic significance of preoperative serum albumin in urothelial carcinoma: a systematic review and meta-analysis. Biosci. Rep. 38(4), 485-496 (2018).

24. Hill PG. The measurement of albumin in serum and plasma. Ann. Clin. Biochem. 22, 565-578 (1985).

25. Pecorelli S. Revised FIGO staging for carcinoma of the vulva, cervix, and endometrium. Bjog. Int. J. Obestet. Gy. 105(2), $103-104$ (2009).

26. Penzel R, Hoegel J, Schmitz W et al. Clusters of chromosomal imbalances in thymic epithelial tumours are associated with the WHO classification and the staging system according to Masaoka. Int. J. Cancer 105(4), 494-498 (2003).

27. Mcmillan DC, Watson WS, O'gorman P et al. Albumin concentrations are primarily determined by the body cell mass and the systemic inflammatory response in cancer patients with weight loss. Nutr. Cancer 39(2), 210-213 (2001).

28. Gupta D, Lis CG. Pretreatment serum albumin as a predictor of cancer survival: a systematic review of the epidemiological literature. Nutr J. 9, 69 (2010).

29. Elinav E, Nowarski R, Thaiss CA et al. Inflammation-induced cancer: crosstalk between tumours, immune cells and microorganisms. Nat. Rev. Cancer. 13(11), 759-771 (2013).

30. Ward EJ, Henry LM, Friend AJ et al. Nutritional support in children and young people with cancer undergoing chemotherapy. Cochrane DB Syst. Rev. 15(8), 112-123 (2015).

31. Laursen I, Briand P, Lykkesfeldt AE. Serum albumin as a modulator on growth of the human breast cancer cell line, MCF-7. Anticancer Res. 10(2A), 343-351 (1990).

32. Seaton K. Albumin concentration controls cancer. J. Natl Med. Assoc. 93(12), 490-493 (2001).

33. Seebacher V, Grimm C, Reinthaller A et al. The value of serum albumin as a novel independent marker for prognosis in patients with endometrial cancer. Eur. J. Obstet. Gynecol. Reprod. Biol. 171(1), 101-106 (2013).

34. Fearon KC, Barber MD, Falconer JS et al. Pancreatic cancer as a model: inflammatory mediators, acute-phase response, and cancer cachexia. World J. Surg. 23(6), 584-588 (1999).

35. Moses AG, Maingay J, Sangster K et al. Pro-inflammatory cytokine release by peripheral blood mononuclear cells from patients with advanced pancreatic cancer: relationship to acute phase response and survival. Oncol. Rep. 21(4), 1091-1095 (2009).

36. Choi DS, Kim HJ, Yoon JH et al. Endometrial cancer invasion depends on cancer-derived tumor necrosis factor-alpha and stromal derived hepatocyte growth factor. Int. J. Cancer 124(11), 2528-2538 (2009).

37. Brenner DA, Buck M, Feitelberg SP et al. Tumor necrosis factor-alpha inhibits albumin gene expression in a murine model of cachexia. $J$. Clin. Invest. 85(1), 248-255 (1990). 